Original Article

\title{
Effect of extracorporeal shock wave therapy on the shoulder joint functional status of patients with calcific tendinitis
}

\author{
Eun-Kyung KIM, PT, PhD ${ }^{1)}$, KwANG-IL KwaK, PT, PhD²)* \\ 1) Department of Physical Therapy, Seonam University, Republic of Korea \\ 2) Department of Rehabilitation Exercises, WE Fitness Center: 162-5 Mareuk-dong, Seo-gu, \\ Gwangju 61998, Republic of Korea
}

\begin{abstract}
Purpose] This study aimed to analyze the effect of extracorporeal shock wave therapy on the shoulder function of patients with calcific tendinitis through a 12-week follow-up. [Subjects and Methods] A total of 34 patients with calcific tendinitis participated in this study. In the extracorporeal shock wave therapy group, 18 patients received 6-week extracorporeal shock wave therapy and 12-week follow-up. The Constant-Murley scale was used to evaluate shoulder joint function. [Results] Analysis of variance showed a significant difference between the measurement periods. The independent t-test showed significant differences between the groups at 2, 6, and 12 weeks. [Conclusion] Extracorporeal shock wave therapy can be an effective treatment method for calcific tendinitis that affects patients' shoulder function.

Key words: Extracorporeal shock wave therapy, Calcifying tendinitis, Constant-Murley scale
\end{abstract}

(This article was submitted Mar. 28, 2016, and was accepted May 23, 2016)

\section{INTRODUCTION}

No specific causes of calcific tendinitis, which is common in women in their forties and fifties, have yet been identified ${ }^{1)}$. Spontaneous dissolution of calcification deposits may improve symptoms but causes pain due to the long dissolution time and discomfort in daily life ${ }^{2,3)}$. Conservative treatments such as the use of nonsteroidal anti-inflammatory drugs, subacromial steroid injection, ultrasonography, radiation treatment, and physical therapy have been used for calcific tendinitis of the shoulder joint ${ }^{4}$. However, the effects of these methods were reported to be limited. Surgical removal under arthroscopy and open techniques can be helpful to improve symptoms when calcific tendinitis is unresponsive to conservative treatment ${ }^{5}$. Needle insertion may cause severe inflammation and damage to tendons ${ }^{6)}$.

Extracorporeal shock wave therapy (ESWT) has been reported to be a noninvasive method, to be associated with decreased enthesopathic pain, and to have a positive treatment effect on calcific tendinitis ${ }^{2,7)}$. However, only few follow-up and physical therapy research studies have been conducted for calcific tendinitis treatment using ESWT. The purpose of this study was to analyze the effect of ESWT on calcific tendinitis through long-term follow-up.

\section{SUBJECTS AND METHODS}

This study included a sample of 40 patients with calcific tendinitis, aged 40 to 65 years, who were hospitalized in or visited P hospital in Suncheon City, Jeollanam-do Province, South Korea. Prior to participation, all the participants were informed of the purpose and methods of the study, and agreed to participate in the study by providing written consent, in accordance with the ethical standard of the Declaration of Helsinki. The participants were randomly divided into the ESWT group (n=20) and

\footnotetext{
*Corresponding author. Kwang-Il Kwak (E-mail: kdream5482@hanmail.net)

(C)2016 The Society of Physical Therapy Science. Published by IPEC Inc.

This is an open-access article distributed under the terms of the Creative Commons Attribution Non-Commercial No Derivatives (by-nc-nd) License $<$ http://creativecommons.org/licenses/by-nc-nd/4.0/>.
} 
Table 1. General characteristics of the study subjects

\begin{tabular}{lcc}
\hline & ESWT group & Control group \\
\hline Gender (male/female) & $7 / 11$ & $4 / 12$ \\
Age (years), mean \pm SD & $50.2 \pm 5.6$ & $53.0 \pm 4.6$ \\
Side (dom/nondom) & $16 / 2$ & $16 / 2$ \\
\hline ESWT: extracorporeal shock wave therapy & \\
dom: dominant; nondom: non dominant &
\end{tabular}

Table 2. Constant-Murley scale scores for each treatment group over time

\begin{tabular}{lcllc}
\hline Group & Before & At 2 weeks & At 6 weeks & At 12 weeks \\
\hline ESWT $^{*}$ & $38.3 \pm 5.6$ & $56.0 \pm 6.3^{\dagger}$ & $72.8 \pm 5.7^{\dagger}$ & $87.7 \pm 7.1^{\dagger}$ \\
Control* $^{\dagger}$ & $40.8 \pm 4.2$ & $47.3 \pm 5.1$ & $52.8 \pm 5.4$ & $62.3 \pm 5.5$ \\
\hline
\end{tabular}

Data are presented as mean \pm SD.

ESWT: extracorporeal shock wave therapy

*Significantly different from the baseline value $(\mathrm{p}<0.05)$.

'Significantly different between the groups $(\mathrm{p}<0.05)$.

control group $(\mathrm{n}=20)$. However, 2 patients in the ESWT group and 4 in the control group wished to withdraw from the study and were excluded. Finally, 34 patients completed the study.

The selection criteria for the participants were patients with calcific tendinitis diagnosed on ultrasonography by a specialist. Patients who were identified to have rotator cuff tear or subacromial bursitis on a clinical test, ultrasonography, and shoulder joint magnetic resonance imaging, and those with neck bone problems, scapulothoracic joint inflammation, pregnancy, and neurological symptoms were excluded.

Table 1 shows the general characteristics of the participants. All the participants received nonsteroidal anti-inflammatory drugs for 6 weeks and 20-minute hot pack placement as basic physical therapy (hot pack), 15-minute transcutaneous electrical nerve stimulation (placing a surface electrode on the aching part of the shoulder joint and stimulating with asymmetrical biphasic pulsed waves of $100 \mathrm{~Hz}$ with a density of 20-30 mA), and 5-minute ultrasonographic therapy with a density of $1 \mathrm{~W} /$ $\mathrm{cm}^{2}, 3$ times per week for 12 weeks. In addition, the treatment group received ESWT using OssaTron Orthotripsy (High Medicial Technology, Kreuzlinern, Switzerland) 960 times, with an energy flux density of $0.14 \mathrm{~mJ} / \mathrm{mm}^{2}$, and a frequency of $4 \mathrm{~Hz}$ or 240 impulses/minute per therapy. ESWT was conducted 3 times a week until 6 weeks, but not from 6 to 12 weeks. Functional assessment of the patients was performed at 2,6, and 12 weeks.

The Constant-Murley scale (CMS), a standardized clinical measurement method for shoulder joint function evaluation, was used in this study. The assessment items were pain (15 points), range of motion (20 points), activities of daily life (40 points), and muscle power (25 points), and scored up to 100 points. A higher point of each item or total score indicated greater shoulder joint function.

For the statistical analysis, the homogeneity test results on the demographic characteristics of the participants were analyzed with the chi-square test and independent t-test. Two-way repeated-measures analysis of variance was used to examine the difference between the measurement periods. An independent t-test was used to analyze the difference between the groups in each period. Statistical analysis was performed by using the PASW 18.0 software for Windows. The statistical significance level was set at $\alpha=0.05$.

\section{RESULTS}

The CMS as a shoulder function evaluation method showed a significant difference in the interaction of the groups according to measurement period ( $<<0.05$; Table 2 ). The treatment group showed a more significant decrease in pain at 2, 6, and 12 weeks compared to the control group $(\mathrm{p}<0.05)$.

\section{DISCUSSION}

Conservative treatment has shown a limited effect on calcific tendinitis of the shoulder joint, and surgical treatment was the only alternative. However, nowadays, ESWT is being discussed as a new treatment method for calcific tendinitis ${ }^{8}$, 9). Shock wave is a type of sound wave that can spread through soft tissues without energy loss. It causes the vibration of tissue molecules and improves the effect of cavitation and fragmentation of calcific crystal to remove the crystal ${ }^{10)}$. The success rate of ESWT for calcific lesions of the shoulder joint has been reported to range from $30 \%$ to $85 \%$. However, results are controversial because of the differences in the number of treatment applications, volume, and treatment method ${ }^{11-13)}$. 
Shock waves are concentrated on focal areas, and the energy at the focal area is defined as energy flux density (EFD) per impulse. Low-energy shock waves have an EFD of approximately $0.1 \mathrm{~mJ} / \mathrm{mm}^{2}{ }^{6}$ ). This study evaluated shoulder function status by using CMS at each period with low-energy shock waves of $0.14 \mathrm{~mJ} / \mathrm{mm}^{2}$. Loew et al. ${ }^{7}$ ) analyzed the effect of ESWT in 30 patients with calcific tendinitis. The results of the 3-month follow-up showed that $75 \%$ of the patients experienced a CMS increase of $30 \%$ and a decrease in pain. The study of Rompe et al. about ESWT (single shot) showed that $72 \%$ of the 40 patients with shoulder joint calcific tendinitis noticed an improvement in symptoms in the CMS test ${ }^{14}$.

This study also showed that ESWT is an effective treatment method because the CMS score increased more rapidly with remarkable shoulder joint function improvement in the treatment group. However, side effects such as local flare or subcutaneous hematoma after ESWT have been reported ${ }^{15)}$. This study showed no side effects due to the application of low-energy shock waves.

The limitations of this study were as follows: the emphases were on the treatment effect because the patients who wanted to receive ESWT were assigned in the treatment group, on the improvement in symptoms due to natural death of calcific tendinitis, and on the effect of nonsteroidal anti-inflammatory drugs on the treatment outcome. However, this study showed that low-volume ESWT was also effective for calcific tendinitis. A better-controlled experimental group and standard protocol for maximizing the treatment effect of ESWT on calcific tendinitis will be needed in future studies.

\section{REFERENCES}

1) Gerdesmeyer L, Wagenpfeil S, Haake M, et al.: Extracorporeal shock wave therapy for the treatment of chronic calcifying tendonitis of the rotator cuff: a randomized controlled trial. JAMA, 2003, 290: 2573-2580. [Medline] [CrossRef]

2) Rompe JD, Rumler F, Hopf C, et al.: Extracorporal shock wave therapy for calcifying tendinitis of the shoulder. Clin Orthop Relat Res, 1995, (321): 196-201. [Medline]

3) Ryu BJ, Ha KW, Lee JY, et al.: Radial extracorporeal shock wave therapy for heterotopic ossification. J Phys Ther Sci, 2016, 28: 701-704. [Medline] [CrossRef]

4) Green S, Buchbinder R, Glazier R, et al.: Systematic review of randomised controlled trials of interventions for painful shoulder: selection criteria, outcome assessment, and efficacy. BMJ, 1998, 316: 354-360. [Medline] [CrossRef]

5) Ogden JA, Alvarez RG, Levitt R, et al.: Shock wave therapy (Orthotripsy) in musculoskeletal disorders. Clin Orthop Relat Res, 2001, (387): 22-40. [Medline] [CrossRef]

6) Farin PU, Räsänen H, Jaroma H, et al.: Rotator cuff calcifications: treatment with ultrasound-guided percutaneous needle aspiration and lavage. Skeletal Radiol, 1996, 25: 551-554. [Medline] [CrossRef]

7) Loew M, Daecke W, Kusnierczak D, et al.: Shock-wave therapy is effective for chronic calcifying tendinitis of the shoulder. J Bone Joint Surg Br, 1999, 81: 863-867. [Medline] [CrossRef]

8) Delacrétaz G, Rink K, Pittomvils G, et al.: Importance of the implosion of ESWL-induced cavitation bubbles. Ultrasound Med Biol, 1995, 21: 97-103. [Medline] [CrossRef]

9) Park C, Lee S, Yi CW, et al.: The effects of extracorporeal shock wave therapy on frozen shoulder patients' pain and functions. J Phys Ther Sci, 2015, 27: 3659-3661. [Medline] [CrossRef]

10) Sapozhnikov OA, Khokhlova VA, Bailey MR, et al.: Effect of overpressure and pulse repetition frequency on cavitation in shock wave lithotripsy. J Acoust Soc Am, 2002, 112: 1183-1195. [Medline] [CrossRef]

11) Speed CA, Richards C, Nichols D, et al.: Extracorporeal shock-wave therapy for tendonitis of the rotator cuff. A double-blind, randomised, controlled trial. J Bone Joint Surg Br, 2002, 84: 509-512. [Medline] [CrossRef]

12) Haake M, Deike B, Thon A, et al.: Exact focusing of extracorporeal shock wave therapy for calcifying tendinopathy. Clin Orthop Relat Res, 2002, (397): 323-331. [Medline] [CrossRef]

13) Lee JH, Jang SH, Cho SH, et al.: Comparison of extracorporeal shock wave therapy and trigger point injection in terms of their effects on pain and bodily functions of myofascial pain syndrome patients. J Phys Ther Sci, 2012, 24: 1069-1072. [CrossRef]

14) Rompe JD, Zoellner J, Nafe B: Shock wave therapy versus conventional surgery in the treatment of calcifying tendinitis of the shoulder. Clin Orthop Relat Res, 2001, (387): 72-82. [Medline] [CrossRef]

15) Seil R, Wilmes P, Nührenbörger C: Extracorporeal shock wave therapy for tendinopathies. Expert Rev Med Devices, 2006, 3: 463-470. [Medline] [CrossRef] 